\title{
Chapter 15 \\ Organic Green Corrosion Inhibitors Derived from Natural and/or Biological Sources for Conservation of Metals Cultural Heritage
}

\author{
Vasilike Argyropoulos, Stamatis C. Boyatzis, Maria Giannoulaki, \\ Elodie Guilminot, and Aggeliki Zacharopoulou
}

\begin{abstract}
In the last decade, there has been an increase in research related to green corrosion inhibitors for conservation of metals cultural heritage to help promote sustainable practices in the field that are safe, environmentally friendly, and ecologically acceptable. The most common are organic substances derived either from natural and/or biological sources: plant extracts and oils, amino acids, microorganisms, and biopolymers. The chapter will provide a review of these substances as corrosion inhibitors for metals conservation, by discussing the state-of-the-art research to date, with a special focus on cysteine. Most of the research has focused on the examination of such inhibitors on metal coupons with or without corrosion products using electrochemical techniques or weight-loss measurements to determine their effectiveness. Some of these studies have also considered the conservation principles for practice, i.e., reversibility of the treatment and the visual aspect of the modification of the treated metal surface. However, before such green inhibitors can be routinely applied by conservators, more research is required on their application to real artefacts/monuments using in situ corrosion measurements. Furthermore, given that the composition of a green inhibitor is highly dependent on its extraction process, research must also involve identifying the specific adsorption models and involved mechanisms to ensure reproducibility of results.
\end{abstract}

\footnotetext{
V. Argyropoulos $(\bowtie) \cdot$ S. C. Boyatzis · M. Giannoulaki

Department of Conservation of Antiquities and Works of Art, University of West Attica, Athens, Greece

e-mail: bessie@uniwa.gr; sboyatzis@uniwa.gr; mgiann@uniwa.gr

E. Guilminot

GPLA Arc'Antique, Nantes, France

e-mail: Elodie.GUILMINOT@1oire-atlantique.fr
}

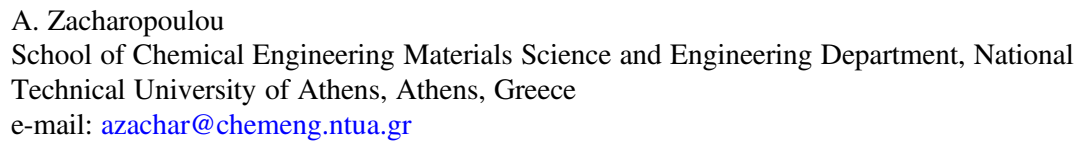


Keywords Green corrosion inhibitors · Conservation · Metals · Cultural heritage · Cysteine $\cdot$ Natural or biological sources $\cdot$ sustainable practice

\section{Introduction}

Corrosion inhibitors are used in conservation of metals cultural heritage to slow down or even prevent their corrosion during pretreatment, stabilization treatment, or storage/exhibition. Protection systems are used for maintenance of metal cultural heritage objects and monuments often with corrosion inhibitors, applied many times with or even in coatings (e.g., varnishes, waxes, and paints), or found in the packing materials used to store the objects. These systems must be effective at protecting long-term important monuments, such as the Eiffel Tower in Paris or rare objects such as the Antikythera mechanism at the National Archaeological Museum in Athens each with millions of visitors each year. There has been much discussion, research, and review into the application of corrosion inhibitors in metals conservation (Keene 1985; Rocca and Mirambet 2007; Cano and Lafuente 2013). In the last decade there has been a trend in conservation research as for industry into the application of green corrosion inhibitors or eco-friendly substances that have biocompatibility in nature. Sustainable conservation practices are growing concern especially given the effects of climate change to the environment (De Silva and Henderson 2011), and for health and safety concerns for conservators, even though there is a lack of exposure studies due to their work-related practices (Hawks et al. 2010; Schrager et al. 2017). As such, conservation research in metals should focus on the use of green materials, and the choices for corrosion inhibitors must conform to applicable standards and regulations concerning toxicity and environmental protection (Sharma and Sharma 2012; Goni and Mazumder 2019). This chapter will discuss and review organic green corrosion inhibitors (OGCIs) derived from natural and/or biological sources for conservation of metals with the aim in understanding their effectiveness, limitations, and way forward in research for conservation.

Specifically, when reviewing and discussing the literature on corrosion inhibitor applications for metals cultural heritage, most often metal surfaces have corrosion products that need to be retained since they preserve their original surface; also, their application occurs in solutions at alkaline or neutral (near-neutral) $\mathrm{pHs}$ either to preserve the metal during stabilization treatments (i.e., removal of corrosive species) or as a modification of the surface as a final conservation step for added protection. For industrial metals, corrosion inhibitors are applied to clean metal surfaces (without corrosion products), and most often in solutions at acidic pHs with the aim to strip the metal of those corrosion products, while at the same time protecting the metal substrate from corrosion.

For metals conservation, corrosion inhibitors can be applied anywhere during the conservation process: before, during, and after conservation. As such, corrosion inhibitors are applied in the following situations: 
Fig. 15.1 The application of tannic acid as a final conservation step in coating cast iron cannon

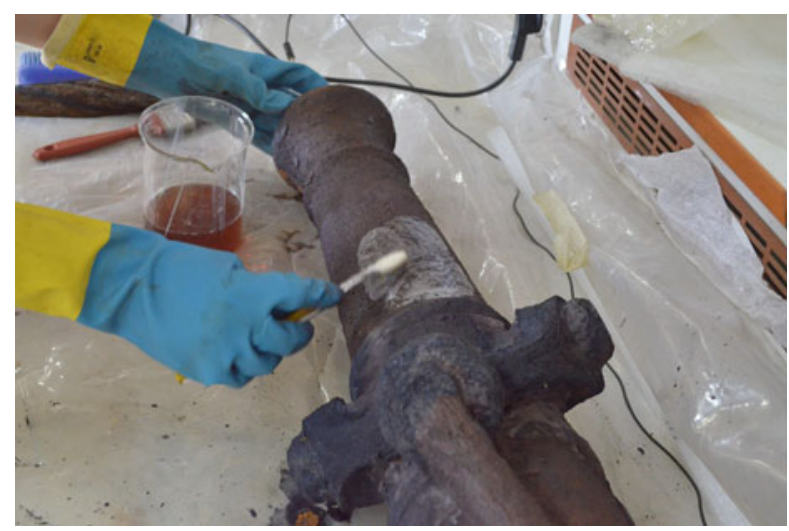

1. In aqueous solutions, where the objects are immersed during their storage prior to treatment and/or during stabilization treatments (e.g., archaeological objects from terrestrial or marine sites);

2. In surface treatments applied with a solvent either by immersion or brush to the objects/monuments as the final step in conservation with or without an additional coating;

3. Included in paints and coating systems to provide added protection to the coated objects/monuments;

4. In vapour phase, as capsules or in packing materials for long-term storage of metal objects/items;

5. As reactive particles found in packaging materials to help produce a microenvironment leading to the preservation of the metal object either before or after conservation.

The conservation field usually follows industry trends in testing the application of new types of corrosion inhibitors. The two best known corrosion inhibitors applied from industry and used in conservation of objects made from copper and iron alloys for over 50 years are benzotriazole (BTA) (Madsen 1967) and tannins (Pelikan 1966), respectively (see Fig. 15.1). These inhibitors are usually applied as surface treatment prior to coating, or even found in coatings systems, such as BTA in Incralac (used to absorb ultraviolet light preventing breakdown of the protective film) (Erhardt et al. 1984; Boyatzis et al. 2017). Today, BTA is classified by the European Chemicals Agency as toxic (ECHA 2019a), but conservators still favour its use, until a suitable replacement is found (Cano and Lafuente 2013).

Industry over the past 10 years has shown a great interest in the use of green corrosion inhibitors for industrial applications, which is apparent by the dramatic increase in the publications on the topic when searching the Web of Knowledge, due to the hazards caused by commonly used toxic corrosion inhibitors (Shehata et al. 2018; Marzorati et al. 2019). Although there has also been conservation research during this period on the topic (see discussion in Sect. 15.3), metal conservators do not yet routinely apply these new green materials for conservation since they want 


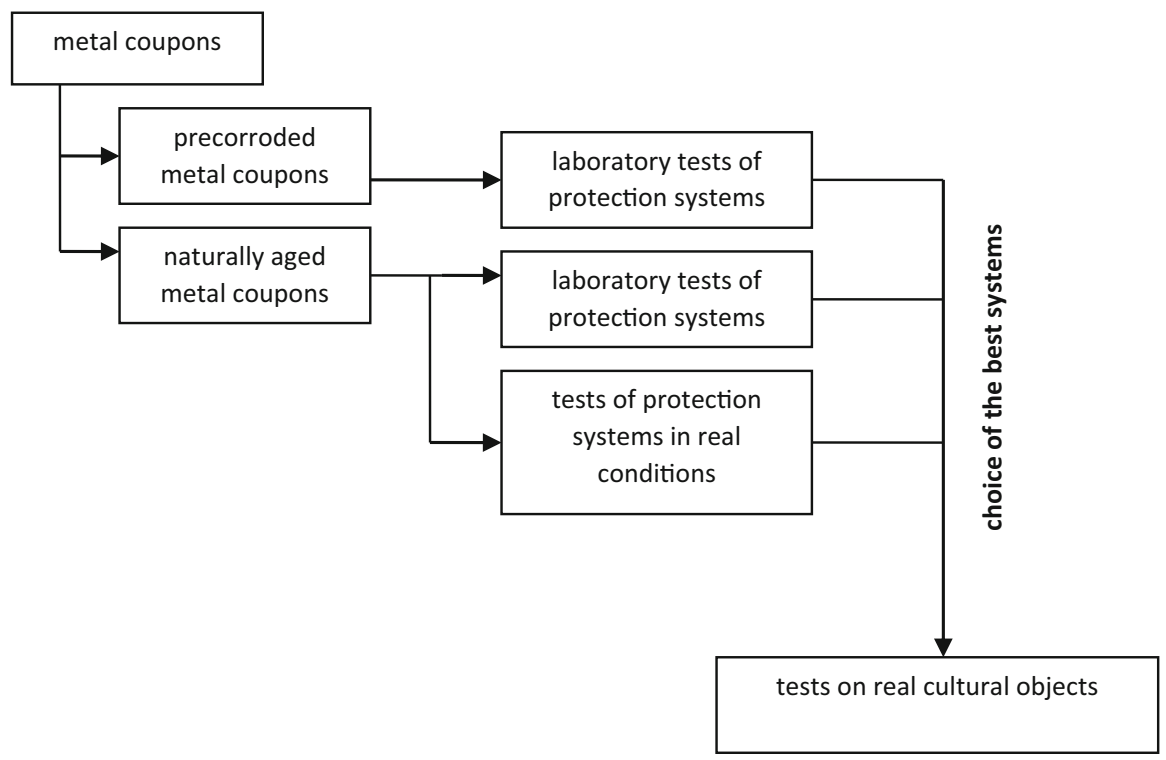

Fig. 15.2 Methodology followed during PROMET project for testing traditional and innovative protection systems for metals cultural heritage

more in-depth research into the long-term effects of these new products on cultural heritage metal objects. As a result, even today many traditional materials (e.g., chemicals including solvents) used by conservators may be unsafe both to their health and to the environment, since their primary concern is the effectiveness at stabilizing or protecting their objects long-term.

Research into green corrosion inhibitors for conservation of metals cultural heritage was greatly influenced by a collaborative project established over 10 years ago under the acronym PROMET entitled: 'Innovative Conservation Approaches for Monitoring and Protecting Ancient and Historic Metals Collections from the Mediterranean Region', financially supported by European project FP6-INCO (2004-2008) (Argyropoulos 2008; De Silva and Henderson 2011). The research results of this project set a milestone in sustainable practices for conservation of metals by:

1. Establishing a protocol for the testing of coatings and corrosion inhibitors on material culture made of metals involving a common methodology for coupon preparation and coating application as well as the performance of accelerated and natural aged corrosion tests (see Fig. 15.2) (Degrigny 2008; Argyropoulos et al. 2013).

2. Supporting and carrying out research into new and safe materials for protecting metal objects, the results of which inspired further research projects into this area (Cano and Lafuente 2013). 


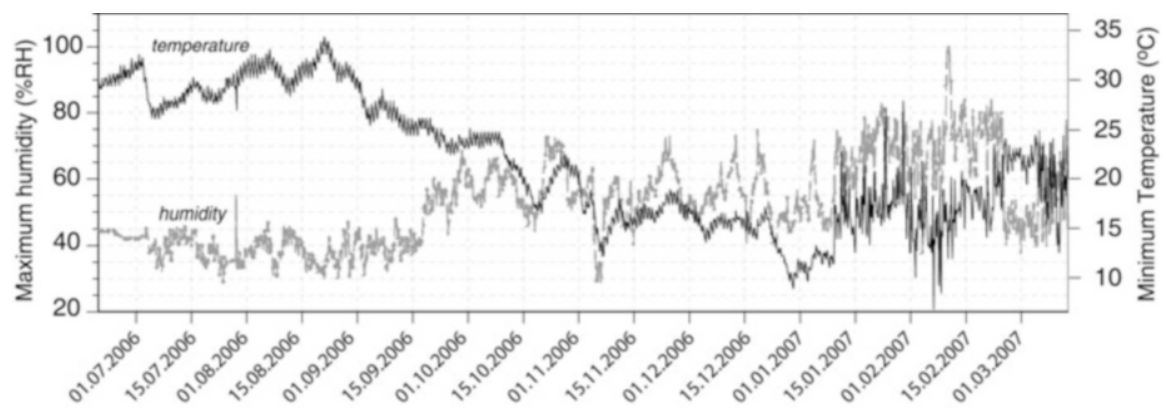

Fig. 15.3 Relative humidity and temperature measurements at the Palace Armoury collection in Malta between May-November 2006

Fig. 15.4 Coating appearance at the end of the accelerated ageing process (ageing cycles defined by the PROMET project) on artificially aged steel PROMET coupons with Paraloid B72® (using a stereo microscope $\mathrm{x} 4$ ) showing filiform corrosion

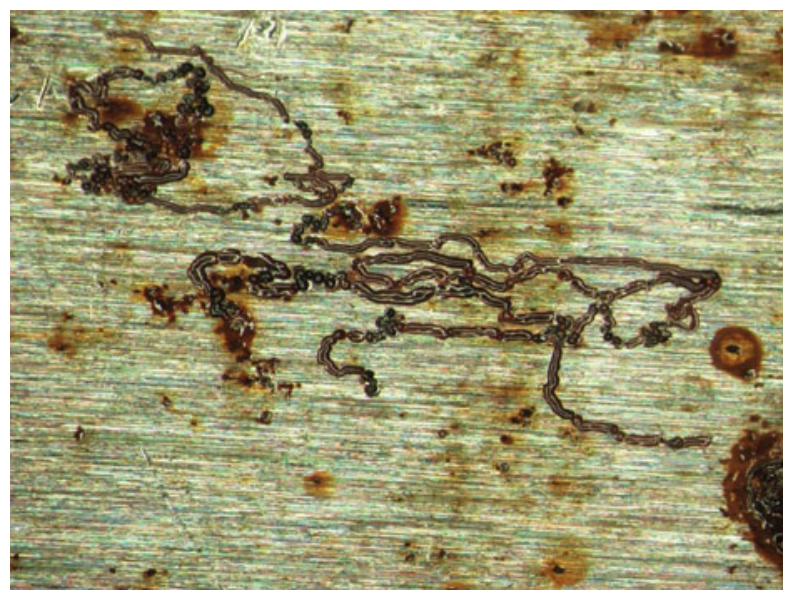

The PROMET project published a survey in 2007 on the use of corrosion inhibitors and coatings by conservators for metals museum collections in the Mediterranean region, which found that BTA in ethanol as a corrosion inhibitor and Paraloid B72 as a coating were the most popular in those countries (Argyropoulos et al. 2007b). However, these materials/practices were often developed and tested for metal objects in northern European and North American museums and were then brought into use in Mediterranean countries by foreigners working on missions in those countries or conservators who received their education abroad. In some cases, some materials and methods were found to be unsuitable for objects stored in a museum environment with high and fluctuating temperature and relative humidity including the presence of salt aerosols from close proximity to the sea (see Figs. 15.3 and 15.4) (Degrigny et al. 2007; Argyropoulos et al. 2007a). Also, the protection of metal collections from active corrosion is often the main concern both for archaeological and historical metal indoor and outdoor collections making the use of corrosion inhibitors and/or coatings essential in the Mediterranean region along with the necessary stabilization treatments. 
In reviewing the literature on the topic presented in Sect. 15.3 of this chapter, countries in the Mediterranean region are the leaders in research of green corrosion inhibitors to cultural heritage metals. This chapter will define the types of green organic corrosion inhibitors commonly used by industry, how they work, and highlight the state-of-the-art research for conservation into these types of inhibitors used in different types of applications. Finally the chapter will provide a summary of the authors' research into cysteine as a corrosion inhibitor for copper alloy metal artefacts and provide a statement for the way forward into research for metals conservation using green organic corrosion inhibitors from natural and biological sources.

\section{Definition of Green Corrosion Inhibitors}

Green corrosion inhibitors are biodegradable and do not contain heavy metals or other toxic compounds (Rani and Basu 2012). Traditionally industry used corrosion inhibitors that were non-biodegradable synthetic organic corrosion inhibitors and traditional inorganic corrosion inhibitors often contained heavy metals, such as chromates, that became restrictive with environmental regulations due to their hazardous effects, causing both problems to human health and/or ecological systems (Popoola 2019). These environmental issues have led corrosion scientists and engineers to move towards the use of green corrosion inhibitors from natural organic compounds and sources that are inexpensive, readily available, environmentally friendly and ecologically acceptable, and renewable (Goni and Mazumder 2019).

\subsection{The Different Types or Classes of Corrosion Inhibitors}

The different types or classification of corrosion inhibitors are either scavengers or interface inhibitors, where the former scavenges aggressive substances from the corrosive medium, and the latter inhibits corrosion through film formation at the metal-environment interface (Popoola 2019).

The best known scavenger type inhibitors used in metals conservation either prevent oxygen induced corrosion or trap volatile gaseous compounds by either trapping or reacting with those compounds. For conservation, examples of products commonly used in packaging for storage/exhibition are Ageless ${ }^{\circledR}$ (Grattan and Gilberg 1994) or RP/ESCAL system (Mathias et al. 2004) for $\mathrm{O}_{2}$ scavengers and activated charcoal or silver particles impregnated in fabrics, e.g., Pacific Silvercloth ${ }^{\circledR}$ for reacting with sulphureous compounds (see Fig. 15.5). There are also many types of oxygen-scavenging compounds that are directly incorporated into packaged materials, such as flexible films, plastics, etc.: one such product is Corrosion Intercept ${ }^{\circledR}$ used for packaging, where the polymer matrix is composed of highly reactive copper particles, making the matrix film reactive and neutralizing 
Fig. 15.5 An iron artefact stored in a sealed microenvironment containing RP/ESCAL to control the relative humidity and the $\mathrm{O}_{2}$ levels with scavenger inhibitor

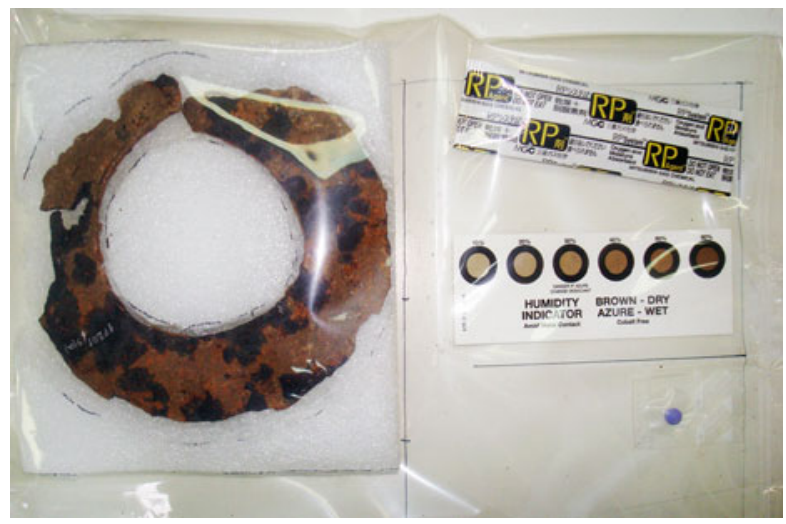

corrosive gases they come in contact with. There are also examples of such films, plastics that are bio-based containing, for example, gallic acid as an oxygen scavenger (Pant et al. 2017), but to date there is no application in conservation to the authors' knowledge.

Interface inhibitors can be classified as either vapour phase or liquid phase, with many known applications in conservation of metals. The vapour-phase inhibitors or vapour corrosion inhibitors (VCI) provide temporary atmospheric corrosion protection especially in closed environments by loosely impregnating wrapping paper inside a closed container. Some popular type paper rolls used for wrapping different types metals from museum collections contain VCI, such as Zerust ${ }^{\circledR}$ and Cortec VpCI films.

However, the most prominent corrosion inhibitors used both by industry and for conservation of metals are the liquid-phase inhibitors, which can be further subdivided into cathodic, anodic, or mixed based on the reaction-type inhibition, which can be any of the cathodic, anodic, or both electrochemical reactions. Cano and Lafuente (2013) provide a good review for these types of corrosion inhibitors used in metals conservation according to the different types of metal alloys. They confirm through their review that the most commonly applied inhibitors to the surface of a copper and iron alloyed objects are BTA and tannins, respectively. They also state that as opposed to industrial applications, for the metal conservation field, interface inhibitors are used to produce surface modifications or films through adsorption onto the metal surface using most often immersion followed by drying and coating. They briefly touch upon research in conservation using green inhibitors, but state that their application for metals conservation is limited.

Like regular corrosion inhibitors, green inhibitors have the same classifications but are derived from organic natural and/or biological sources as opposed to synthetic and for inorganic do not contain heavy metals. For the latter, some rare earth compounds (e.g., $\mathrm{CeCl}_{3}$ and $\mathrm{LaCl}_{3}$ ) are considered as inorganic green corrosion inhibitors and for the former natural and/or biological sources for organic green corrosion inhibitors are plants, drugs, amino acids, surfactants, biopolymers, and ionic liquids (El Ibrahimi et al. 2020). Others classify organic green inhibitors 


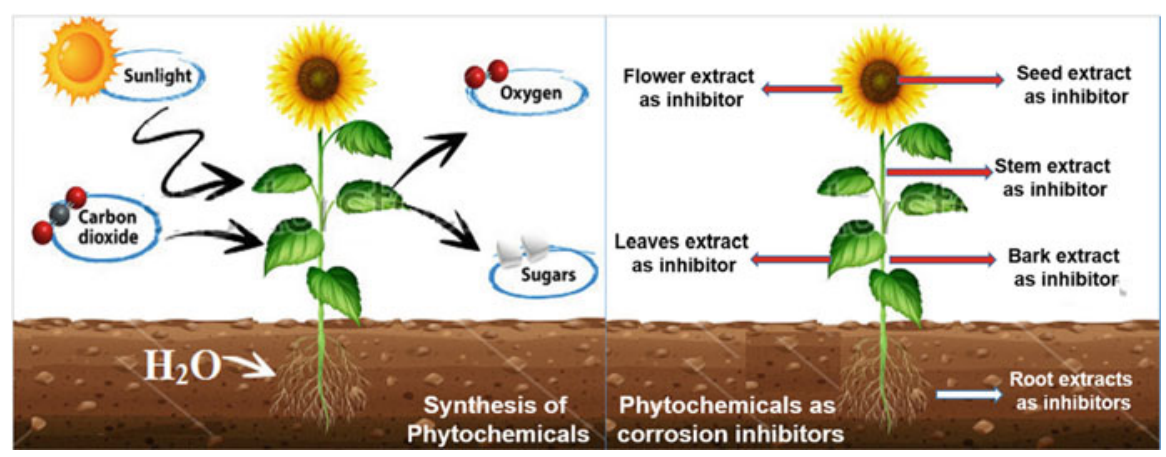

Fig. 15.6 Plant extracts as corrosion inhibitors can be taken from a diverse part of the plants (Reproduced from (Verma et al. 2018) with permission from Elsevier)

according to their natural compounds or products they contain, such as amino acids, alkaloids, phenols and polyphenols, fatty acids (Marzorati et al. 2019), or as biological (chitosan, amino acids, bacteria, and fungi), vegetable (plant extracts, shells, tannins), and pharmaceutical drugs (Montemor 2016). Regardless of their classification, approximately $80 \%$ of organic corrosion green inhibitors are categorized as mixed inhibitors that protect the metal from corrosion by chemical and physical adsorption and film formation (Popoola 2019).

Lastly, it is important to remember that even green inhibitors may not always be inexpensive or even environmentally friendly due to the cost and time needed to extract and purify naturally occurring substances, like from some plants (see Fig. 15.6 (Verma et al. 2018)), drugs or ionic liquids (El Ibrahimi et al. 2020). Also later authors state that organic solvents may be needed for the extraction process, which can also damage the environment. Thus, abundance, renewal, and bio disposal are the key for applying such green inhibitors in real situations (Montemor 2016).

The rest of this chapter will only focus on organic green corrosion inhibitors derived from natural and/or biological sources, which are the most commonly researched by industry and conservation. It does not include discussions of organic ligands or synthetic surfactants as corrosion inhibitors, such as salicylaldoxime and their derivatives (Abu-Baker et al. 2013; Abu-baker 2019) and Hostacor IT (Argyropoulos et al. 1999), since although eco-friendly and biodegradable, they are not obtained from natural and/or biological sources.

\subsection{How Do They Work?}

Green inhibitors have properties that are similar to the 'non-green' inhibitors (Kesavan et al. 2012). The most commonly used in conservation as for industry are corrosion interface inhibitors, which act by: (i) forming a film that is adsorbed on 
the metal surface; (ii) producing corrosion products that acts as a passivator; and (iii) yielding precipitates that can eliminate or inactivate aggressive constituents (Goni and Mazumder 2019). Their action on the metal surface takes place via physical or chemical adsorption which removes water or corrosive species from the surface by providing a barrier film formation (Goni and Mazumder 2019). Organic green corrosion inhibitors are effective due to the availability of organic compounds with polar functional groups with $\mathrm{N}, \mathrm{O}$, and $\mathrm{S}$ heteroatoms, which have a shielding effect and by repelling aqueous corrosive species away from the metal surface (Popoola 2019).

The most common organic green inhibitors to contain these heteroatoms, which act to inhibit metals from corrosion are: derived from plant extracts adsorbing on the metal surface and forming a compact barrier film (Sharma and Sharma 2012); amino acids which contain molecules with functional groups like carboxyl (-COOH) group, amino (- $\left.\mathrm{NH}_{2}\right)$, and $\mathrm{S}$ thiol (Goni and Mazumder 2019); and drugs because they are synthesized from natural products that contain the presence of heteroatoms, benzene ring, and heterocycles, such as thiophenes, pyridine, isoxazoles (Goni and Mazumder 2019). Also, natural biopolymers such as chitosan are known to have good complexing qualities with their $-\mathrm{NH}_{2}$ groups with metallic ions that can lead to corrosion inhibition in some cases (Jmiai et al. 2017).

Another type of organic green corrosion inhibitor are surfactants which are made up of two parts, a polar hydrophilic group and a nonpolar hydrophobic group, where the former adsorbs onto the metal surface. The charge on the polar head group classifies whether the surfactants are classified as anionic, cationic, nonionic, or zwitterionic (Malik et al. 2011). As well, carboxylates on copper alloy artefacts, where the reaction between the copper ions and the carboxylates leads to the precipitation of metal carboxylates, such as $\mathrm{Cu}\left(\mathrm{C}_{10}\right)_{2}$ (metal soaps) on the surface of the corrosion products layer resulting inhibition; the soaps act as surfactant-type corrosion inhibitor due to the carboxylate part of the molecule providing a hydrophilic character, but have also hydrophobic properties, in relation with the aliphatic chain (L'Héronde et al. 2019). Linseed oil in paints is another type of surfactant corrosion inhibitor used as a traditional method to inhibit corrosion of the copper substrate for oil paintings (Pavlopoulou and Watkinson 2006).

In a completely different action are those of bio-based treatments that convert unstable corrosion products or corrosive species on metals to stable corrosion products and inhibit any further corrosion. One type of bio-based treatment which leads to inhibition of copper alloy coupons with corrosion products involves the use of fungal strain known for their ability to produce oxalic acid; when used it can convert the atacamite layer completely into copper oxalates, which results in enhancement of the surface inhibition against corrosion (Albini et al. 2018). For iron alloys, microorganisms in the form of bacteria have been used to transform ferric iron corrosion products (goethite and lepidocrocite) into stable ferrous ironbearing minerals (vivianite and siderite) (Kooli et al. 2019). 


\section{Conservation Research into the Application of GOCIs}

The oldest known use of a natural green corrosion inhibitor for metals probably occurred when iron and copper alloys replaced wood for moving parts in machinery and vegetable oils were used as lubricants to protect metal against wear and corrosion (Anderson 1991). Historically writings by Theophilus in the Middle Ages indicate that linseed oil was commonly used in recipes for coating iron metal as in varnishes (Sabin 1904). Linseed oil is known to form a protective film on iron, copper, and other metals by oxidative drying and was often used as a primer for painted historical metals, often containing metal salts such as lead, etc. to help accelerate the drying process (Pavlopoulou and Watkinson 2006; Juita et al. 2012). Today, linseed oil continues for industry to be one of the most popular seed extracts for corrosion inhibition used in surface treatments, coatings, and encapsulated to prepare self-healing coatings (Montemor 2016; Leal et al. 2018). In the history of conservation of cultural heritage metals, the most popular green corrosion inhibitor used is tannic acid, and the first mention of its application was as a thin tannin wash for the cast iron roof of Big Ben in London in the 1950s (Turner 1985).

Today, research into new materials for the protection of metals cultural heritage must not only consider the sustainability in using such materials, but also other important principles for conservation practice: the reversibility of the treatment and the visual aspect of the modification of the treated metal surface. The discussion below provides a summary of research publications in conservation for organic green corrosion inhibitors from natural and/or biological sources, which are described in this section according to the type of source of their derivation, most common plant extracts and oils and biological (i.e., amino acids, microorganisms, and biopolymers).

\subsection{Plant Extracts}

The best known and commonly used corrosion inhibitor from a plant extract used in conservation for rusted iron is tannic acid (Pelikan 1966; Logan 2014). Tannin is present in many types of plant material and is obtained commercially from galls of oak, sumac, and willow and occurs in green algae, mosses, brown seaweed, ferns, pore fungi, and in about one-third of the families of flowering plants (Hem 1960). Tannic acid is known to react with metallic iron or rust precipitating ferric tannates to form a protective layer with corrosion inhibiting properties (see Fig. 15.7 (Xu et al. 2019)) and is often used in formulations of primers for paints (Iglesias et al. 2001). Many commercial rust convertors contain tannic acid and are applied in the successful protection of historic iron (Church et al. 2013). Tannic acid mixture containing orthophosphoric acid is commonly used to coat archaeological iron at the end of a conservation treatment (Argyropoulos et al. 1997). The limitations of tannic acid are 


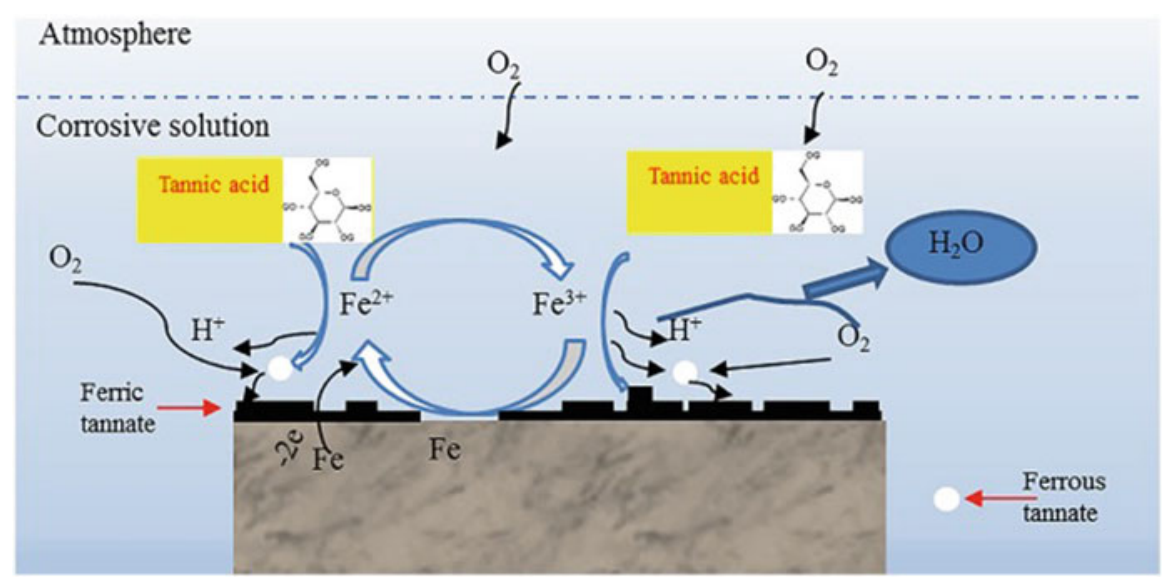

Fig. 15.7 Schematic illustration of corrosion process of carbon steel in corrosive solution with tannic acid (Reproduced from (Xu et al. 2019) with permission from Elsevier)

that for rusted iron it converts the surface colour from reddish to black, and in some cases the protection for iron was found not to be good (Cano and Lafuente 2013).

Other studies have successfully used plant extracts as corrosion inhibitors in conservation, but to date were only tested on metal coupons with and without corrosion products:

For copper alloys:

1. An electrochemical study used a tannins extract of Aloe vera (TAV) (Benzidia et al. 2018) as a corrosion inhibitor for Bronze $\mathrm{B} 66$ in $3 \% \mathrm{w} / \mathrm{v} \mathrm{NaCl}$ solution and $150 \mathrm{ppm}$ of the inhibitor after 24 hours of immersion proved inhibition of the metal (Benzidia et al. 2019). This research was confirmed by another conservation laboratory, where the use of Aloe vera extracts in $3.5 \% \mathrm{w} / \mathrm{v} \mathrm{NaCl}$ solution was tested using electrochemical methods on $\mathrm{Cu}-\mathrm{Sn}$ alloy coupons, and also documented colour changes to the metal surface using different concentrations of the inhibitor (Abdelwahab et al. 2018).

2. Bronze metal immersed in different concentration of extract of Salvia hispanica seeds in a simulated acid rain solution was found to protect it from uniform type of corrosion, but not completely from a localized type of corrosion (LariosGalvez et al. 2017).

For iron alloys:

1. Cast iron coupons, the use of caffeine or nicotine applied in Paraloid B72 was used to increase the coating's resistance at high humidity, but the study did not mention the metal surface colour appearance (Barrera et al. 2019).

2. Cor-Ten steel coupons (often used for modern and contemporary artworks), the use of natural extract of Brassica campestris was applied to the surface and tested in $3 \% \mathrm{w} / \mathrm{v} \mathrm{NaCl}$ solution (Casaletto et al. 2018). The electrochemical study found that Brassica campestris, a widespread plant in Southern Europe, was effective at 
inhibiting corrosion of Cor-Ten steel coupons in conditions similar to coastal areas and harsh-weather environments.

3. For chloride contaminated rust samples (akaganeite), its transformation to stable form of oxides with the fruit extract of Emblica officinalis (Sanskrit name: Amla), naturally derived from a tree abundantly found in tropical climates of the world (Pandya et al. 2016). The study tested the corrosion inhibitor solution on carbon steel samples exposed in a salt spray chamber to produce akaganeite and found the fruit extract containing gallic acid dissolved the unstable rust by transforming it into magnetite and by forming a protective black layer of iron gallate on the surface of these transformed oxide particles.

\subsection{Plant Oils}

The best known corrosion inhibitor from vegetable oils (colza, sunflower, and palm) tested for conservation for metals is salts of carboxylic acids on iron, copper, and lead alloys (Rocca and Mirambet 2007; Hollner et al. 2010) and can also be classified as surfactant-type corrosion inhibitor. As early as 2004, dicarboxylates were found to be good inhibitors for conservation to replace toxic chromates during rinsing of iron objects after acid stripping (Thurrowgood et al. 2004). For lead, $\mathrm{NaC}_{10}$ was found to inhibit corrosion in acetic acid-enriched solutions by the formation of a protective layer composed of the metallic soap, $\mathrm{Pb}\left(\mathrm{C}_{10}\right)_{2}$ (Rocca and Mirambet 2007). However, recent unpublished research has found that $\mathrm{Pb}\left(\mathrm{C}_{10}\right)_{2}$ is not as effective as $\mathrm{Pb}$ oxides for conservation purposes (Guilminot Personal communication, 2019). For copper alloys, while the carboxylic acid solutions applied with ethanol were found to inhibit the corrosion of copper, the resulting blue colour of the copper carboxylate formed was not suitable result for cultural heritage metals (Elia et al. 2010). For iron alloys, during the PROMET project, $0.1 \mathrm{M} \mathrm{NaC}_{10}$ and $\mathrm{HC}_{10}$ (carboxylatation solution) were tested and compared for inhibiting corrosion on PROMET iron coupons, the latter was found to have the best performance (Hollner et al. 2010). However, the study found that the immersion of the iron coupons in carboxylatation solutions caused a very soft red-orange colouration of the surface, characteristic of the precipitation of a thick iron carboxylate protective layer that may not be suitable for conservation purposes. When the same inhibitor was applied using a brush on a real object, a torpedo belonging to the National Maritime Museum of Paris, stored in a boathouse in an uncontrolled environment, the surface appearance could be controlled using a brush application and any colour changes to the surface could easily be removed with ethanol. Thus, the treatment was found to be effective and reversible. Recent research into $\mathrm{NaC}_{10}$ treatment by the same research group found that corrosion inhibition mechanism was based on a chemical conversion of the reactive iron oxyhydroxide, as lepidocrocite, into iron carboxylates (or iron soaps), which inhibits the electrochemical activity of FeOOH-type phases and blocks the dissolution of FeOOH (see Fig. 15.8) (Rocca et al. 2019). 


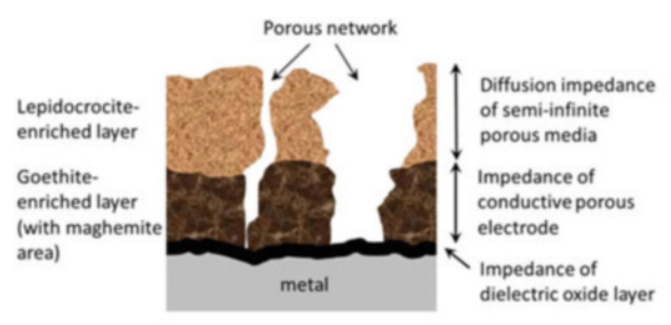

a)

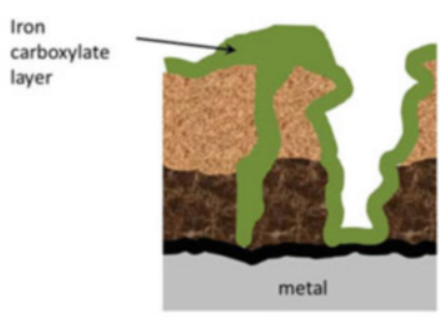

b)

Fig. 15.8 (a) Schematic structural model of the 'metal/CL' system; (b) $\mathrm{HC}_{10}$-treated structure of 'metal/CL' system (Reproduced from (Rocca et al. 2019) with permission from Elsevier)

Another research group that has been very active in developing green corrosion inhibitors for conservation is from the Department of Chemistry at the University Ibn Tofail, in Kenitra, Morocco. They have participated in many national and EC projects and studied plant oils from seeds, as well as plant extracts that are commonly grown in the Mediterranean region as green corrosion inhibitors for metals cultural heritage. Their research has led to patent a green corrosion inhibitor known as Opuntia ficus indica $(\mathrm{OTH})$ from a cactus that originates from Mexico and is very widespread in Morocco (Hammouch et al. 2013). The formulation preparation called OTH contains Opuntia fatty acid, triethanolamine, and $\mathrm{KOH}$ and is easy to apply on metal surfaces and totally reversible in ethanol (Hammouch et al. 2007a). For the PROMET project, it was tested both on the iron and copper alloy coupons produced for the project. For the iron alloy coupons, application of pure OTH applied as brush as opposed to 1 hour immersion in $0.2 \% \mathrm{w} / \mathrm{v}$ OTH in ethanol (48 hours drying) was more effective at protecting them during mild corrosive conditions (Hammouch et al. 2007b). However, during the PROMET project, when OTH was compared to $\mathrm{HC}_{10}$ (carboxylatation solution) (discussed above) on iron coupons in Rabat museum, the latter was found to be more effective during natural ageing (Degrigny 2008).

The same research group in Morocco has continued to study other types of plant oils for iron alloys tested in acidic solution to simulate the atmospheric acid rain of an industrial urban area, such as Nigella sativa (Chellouli et al. 2014; Chellouli et al. 2016), Jatropha curcas seeds oil (Zouarhi et al. 2018), and Ceratonia siliqua seeds oil (Abbout et al. 2018). Their research used electrochemical and weight-loss measurements on iron alloy coupons to determine if various compositions of the plants' oils in acidic solutions are effective. Again the research shows promising results on the coupons, but would require more research on real artefacts with natural ageing tests. 


\subsection{Biological}

Other types of green inhibitors derived from biological and/or natural sources where there has been research in conservation metals are as follows: amino acids and their derivatives, microorganisms, biopolymers, and even bee products. The discussion on amino acids is given in Sect. 15.4 where many researchers have considered the use of cysteine as a replacement corrosion inhibitor to BTA for copper alloys. However, notable mention is given here to the study of the natural amino acid derivative, L-methionine methyl ester, found to be an effective replacement corrosion inhibitor to toxic thiourea in citric acid pickling solutions for mild steel artefacts (Otieno-Alego et al. 2004).

Recently, microorganisms are being investigated for use in the stabilization of metals in cultural heritage, by converting 'active' corrosion products or corrosive species to stable corrosion products, 'biopatina' (Joseph et al. 2012). For copper alloys, a specific strain of Beauveria bassiana isolated from vineyard soils has shown the best performance when applied to copper alloy coupons with corrosion products to convert copper hydroxysulfates and hydroxychlorides into copper oxalates (Albini et al. 2018). Albini et al. (2018) also compared their bio-based treatment to BTA treatment in terms of conversion of corrosion stabilization of a patina composed of copper chlorides, and the bio-based treatment was found to be more effective than BTA.

For iron alloys, two Aeromonas strains (CA23 and CU5) were used by Kooli et al. (2019) to transform iron corrosion products (goethite and lepidocrocite) into stable ferrous iron-bearing minerals (vivianite and siderite). These authors tried to establish a prototype treatment for archaeological iron with partial success using a commercial gel to apply bacteria to nails as test pieces in an attempt to convert the reactive corrosion layer into chemically stable iron minerals; however, their prototype treatment was not tested for chloride-containing iron corrosion products, and the production of undesirable products and abiotic reduction was also observed.

Recent research is now focusing on biopolymers such as chitosan to act as a barrier layer (coating) and reservoir for corrosion inhibitors for protecting $\mathrm{Cu}$ alloyed artefacts, where the polymers can easily be removed by water avoiding the use of toxic solvents (Giuliani et al. 2018). Chitosan is derived from the polysaccharide chitin, and sources of chitin are structural components of the shells of crustaceans, such as shrimps, lobsters, and crabs. Montemor (2016) in his review states that chitosan is used to form thin coatings to protect metals given that under certain conditions it acts as a corrosion inhibitor, but also, the chitosan layer can be used as reservoir for other corrosion inhibitors, for enhancing protection of metals. For conservation research, the chitosan coating was loaded with two corrosion inhibitors that were separately tested and compared, the classic BTA and less toxic mercaptobenzothiazole (MBT) (Giuliani et al. 2018). The study highlights the synergic effect between chitosan and corrosion inhibitor on the protection of copper alloys, since it showed the chitosan coating consisting of a first layer of pure inhibitor and a second layer of pure chitosan has a significantly lower stability and 


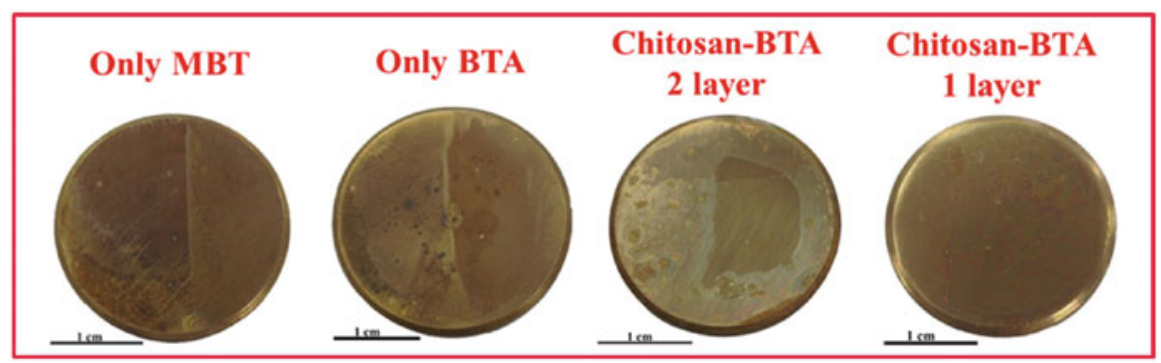

Fig. 15.9 Photographs of CNR128 disks coated with only MBT, only BTA, chitosan-BTA prepared by a two-step deposition, and chitosan-BTA obtained by a one-step procedure after the accelerated corrosion treatments. In the images of only MBT and only BTA are visible both the film (left half) and the alloy bare after film removal (right half) (Reproduced from (Giuliani et al. 2018) with permission from Elsevier)

transparency than the mixed chitosan/inhibitor coating (see Fig. 15.9). The study confirms that the polymer matrix probably acts as an inhibitor reservoir and also contributes to the formation of a barrier layer, thus improving the protective properties.

Finally, bee products (propolis) have been tested on clean bronze using electrochemical techniques and were found to be an effective green corrosion inhibitor in aerated weakly acidic solution ( $\mathrm{pH} 5$ ) that simulates acid rain in an urban environment (Varvara et al. 2017).

\section{Amino Acids: Cysteine as a Corrosion Inhibitor for Copper Alloy Artefacts}

For conservation purposes, the most studied amino acid type corrosion inhibitor has been cysteine for copper alloy artefacts presented in this section below. There has also been a wealth of research into the application of cysteine as a corrosion inhibitor for metals for industrial applications in different media (Raja et al. 2014), to metallurgy, pure chemistry, medicine, industrial chemistry, soil science, and environmental science (Vieira et al. 2011). Given its myriad of applications for various industries/fields, such as food, cosmetics, pharmaceuticals, there are various approaches to naturally isolate cysteine at an industrial scale from the keratin of animal sources as well as plants, and it is only sold in its L form (Hashim et al. 2014). L-cysteine as an amino acid from proteins with three functional groups (thiol, amine, carboxylic) can interact with metals to form complexes (see Fig. 15.10). Between media $\mathrm{pH}$ range of 1.91 and 8.16 , its thiol group is strongly attracted to soft metal ions, and cysteine solutions can completely oxidize to cystine within a short period of time especially with metal ions in solutions (Berthon 1995).

For $\mathrm{Cu}$ and its alloys at neutral $\mathrm{pH}$, it has been suggested when cysteine is used as a corrosion inhibitor it is adsorbed onto the metal surface, by forming a complex and 


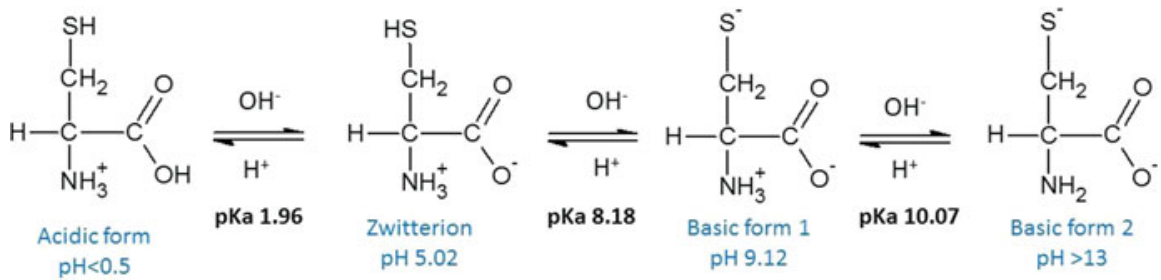

Fig. 15.10 The forms of cysteine depending on the $\mathrm{pH}$ of the medium. $\mathrm{pH}$ values from Lehninger, Biochemistry, fourth Edition (2005), 98

behaving as a cathodic corrosion inhibitor to $\mathrm{Cu}$ corrosion by retarding the transfer of $\mathrm{O}_{2}$ to the cathodic sites of the $\mathrm{Cu}$ surface (Ismail 2007). One recent study concluded that for synthesized $\mathrm{CuCl}$ (nantokite) on $\mathrm{Cu}$ wire treated by immersion in simulated acid rain solution containing $5 \mathrm{mmol} / \mathrm{L}$ cysteine for 2 hours, an inhibition film was formed in $\mathrm{Cu}(\mathrm{I})$ state (Wang et al. 2015). They determined using X-ray photoelectron spectroscopy that the cysteine molecules were chemically adsorbed on $\mathrm{CuCl}$ surface and formed coordination bonds with $\mathrm{Cu}^{+}$-atoms through thiol S-atoms and amino $\mathrm{N}$-atoms.

In metals conservation, L-cysteine has been widely tested as a replacement corrosion inhibitor to BTA and applied in the following ways:

1. Corroded bronze coupons (with nantokite formation) and real bronze artefacts by immersion in water at $0.15 \mathrm{M}$ for 24 hours (Gravgaarda and van Lanschot 2012);

2. Corroded copper and tin bronze by immersion in ethanol at $0.01 \mathrm{M}$ for 24 hours (Abu-Baker et al. 2013);

3. Naturally aged copper coupons with organic materials and real marine brass composite artefact with textile by immersion $1 \% \mathrm{w} / \mathrm{v}$ in $20 \% \mathrm{w} / \mathrm{v}$ PEG400 treatments for one month and 10 days, respectively (Zacharopoulou et al. 2016; Argyropoulos et al. 2018);

4. On a marine tinned copper medieval frying pan as a final surface coating as $1 \%$ $(w / v)$ in deionized water applied using a brush for two hours over a period of three days (Argyropoulos et al. 2017).

All studies found colour changes to the corrosion layers (greying effect) with the cysteine application, which increases in darkening depending on the solutions and modes of application and/or immersion times from grey to a black colour see Fig. 15.11a and $\mathrm{b}$.

Abu-Baker et al. (2013) found with their electrochemical measurements that with increasing amounts of tin in the bronze alloy, the strength of the inhibitor's chemical adsorption on the surface of the alloy increases or its corrosion inhibition efficiency. Further work by Argyropoulos et al. (2018) found that immersion in cysteine for copper alloys results in producing cystine from the oxidation of cysteine, where the presence of $\mathrm{Fe}$ or $\mathrm{Cu}$ ions serves as a catalyst in this reaction. This oxidation reaction results in reducing metal ions, which form a metal ion cystine complex on the surface of the material, and producing either a soluble or insoluble cysteine/cysteinate 
Fig. 15.11 (a and b) The copper alloy firehose before and after treatment in 5\% $(\mathrm{v} / \mathrm{v})$ PEG400 with $1 \%(\mathrm{w} / \mathrm{v})$ cysteine solution in deionized water. After treatment the firehose was dried out in a humidity chamber at above $70 \% \mathrm{RH}$ during the summer period. No signs of active corrosion were apparent on the copper alloy. The object remains stable to date
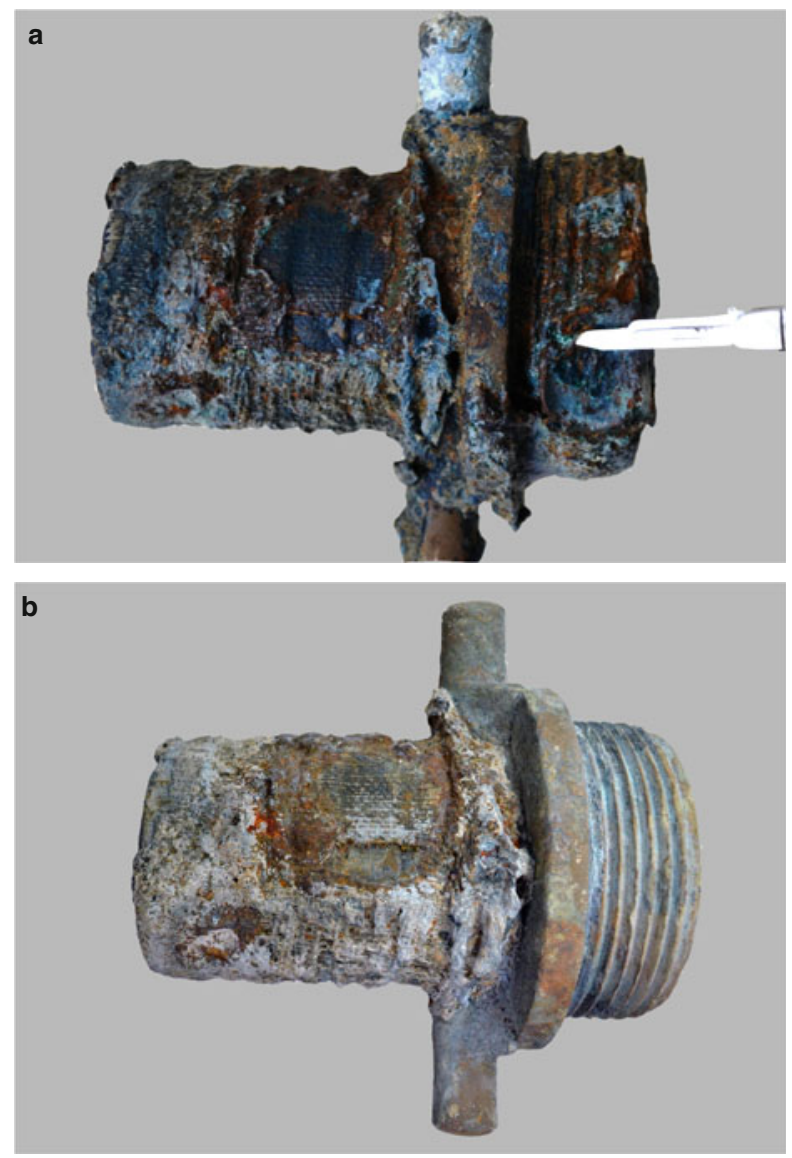

complex with metal ions and cystine precipitate, respectively, in the solutions (Argyropoulos et al. 2018). The greying effect is most likely a result of the metal ion cystine complex on the surface.

Apart from copper coupons and artefacts tested, some interesting results were found in authors' study on the treatment of organics, such as leather in $20 \%(\mathrm{v} / \mathrm{v})$ PEG400 solutions in deionized water with and without $1 \%$ L-cysteine for one month with copper coupons (see Fig. 15.12) (Argyropoulos et al. 2018). In the PEG-treated leather specimen without cysteine (as seen in the difference Fourier-transform infrared spectroscopy (FTIR) spectrum, Fig. 15.13), it seems that tannin is being removed to some degree (pointed by the negative peaks at $1190-1160 \mathrm{~cm}^{-1}$ ) which may cause destabilization of leather; this is accompanied by some change in the structure of protein material, as seen by the observed differences of the amide I peak at $1650 \mathrm{~cm}^{-1}$. In the PEG+cysteine treated leather specimen (see Fig. 15.14), the basic leather infrared peaks remain similar to those in PEG-treated sample; however, quantities of residual cystine are clearly observed, evidence for oxidation of cysteine 


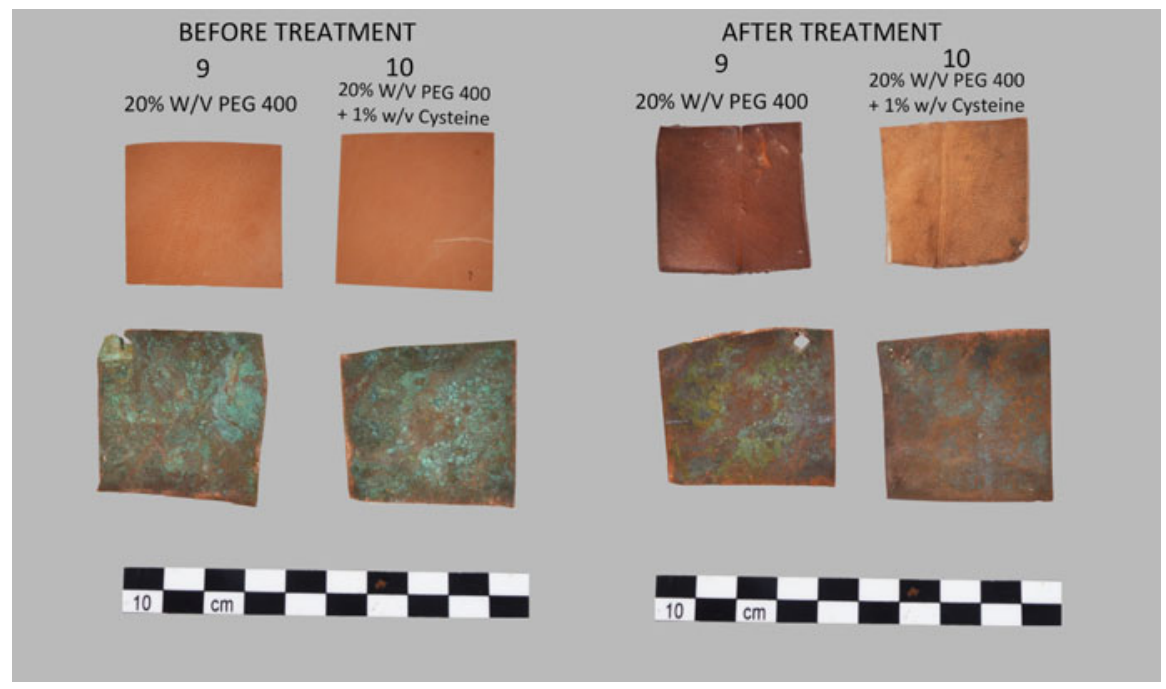

Fig. 15.12 Naturally aged copper coupons with calf leather treated in 20\% (w/v) PEG400 solutions with and without cysteine for one month (before and after treatment)

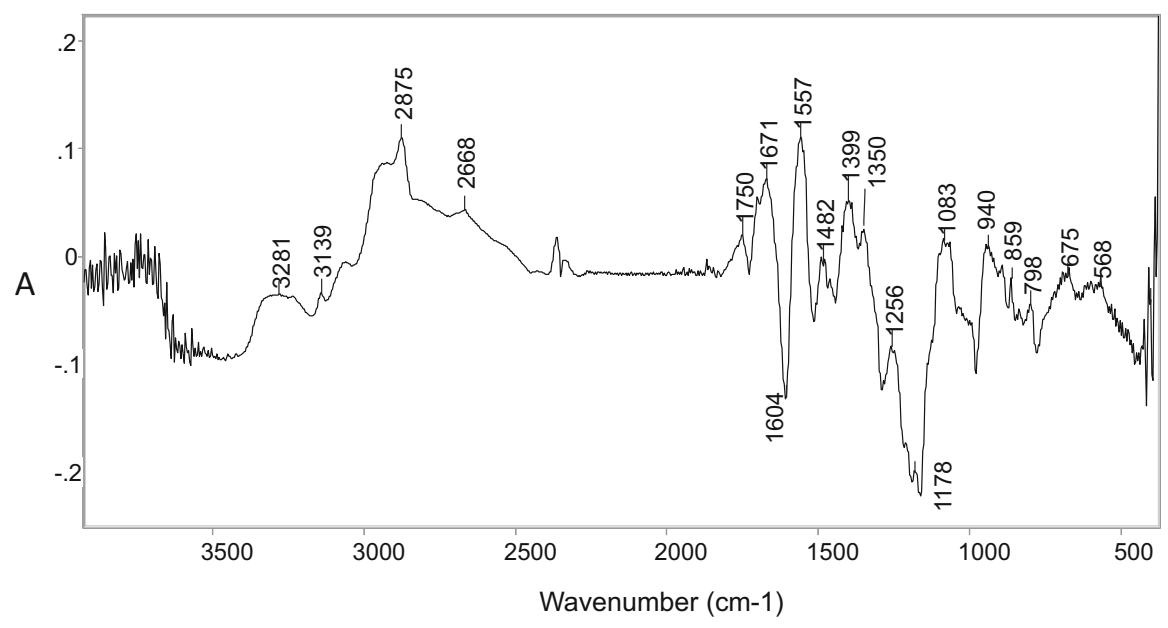

Fig. 15.13 Difference spectrum: [PEG400 treated leather-untreated leather]: the spectrum of the initial leather sample is being subtracted from that of PEG-treated sample one. Positive peaks (pointing upwards) show added features, while negative peaks pointing downwards show removed/ decreased features

towards cystine under the conditions of the experiment. It appears that the tannin removal which took place in the PEG400 solutions alone leading to colour change was inhibited when cysteine was added to the PEG400 solution. Cysteine is listed as a substance that is used by leather and textile treatment products by the European 


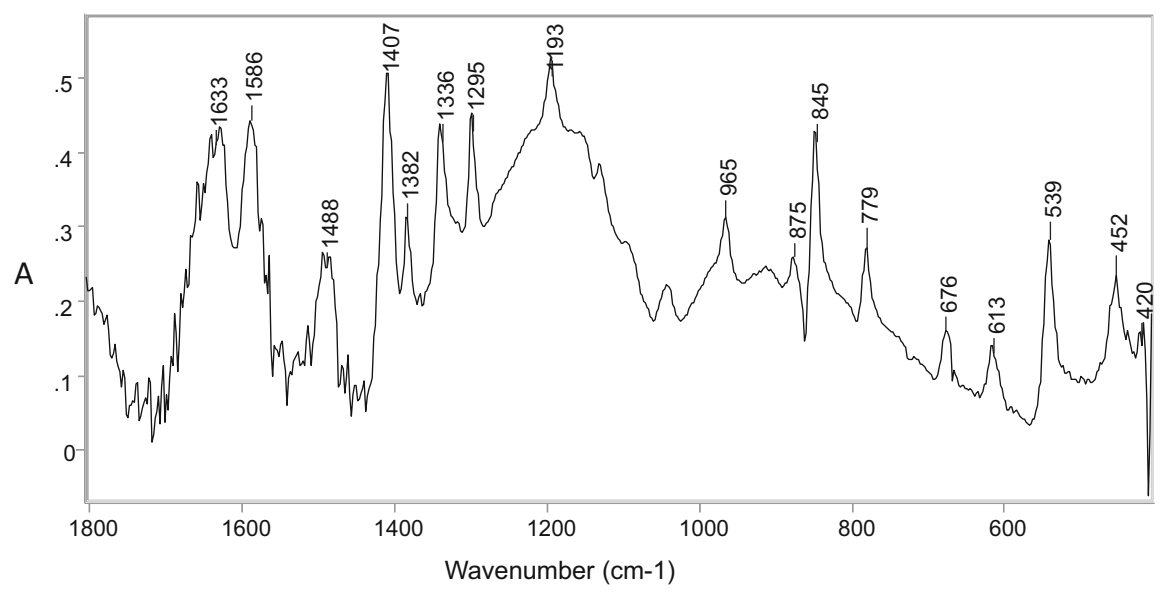

Fig. 15.14 Difference spectrum (zoomed-in area $1800-400 \mathrm{~cm}^{-1}$ ): the spectrum of PEG-treated sample is being subtracted from that of PEG+Cys treated one, shows the effect of cysteine treatment on leather. Positive peaks (pointing upwards) show added features, while negative peaks pointing downwards show removed/decreased features

Chemical Agency (ECHA 2019b). However, more research is also needed to understand the effect of cysteine+PEG400 solutions on wet organic materials with or without metals.

The application of cysteine to copper and its alloys for conservation purposes found interesting results but with limitations, such as colour changes to the surface appearance. However, brush application did reduce colour changes and has been found to be effective on real marine artefacts tested in Greece as a coating after conservation stabilization treatment (see Figs. 15.15a, b).

\section{Where Do We Go from Here?}

Going green is the trend today for conservation professionals in their workplaces, where the use, production, and disposal of the materials they use to treat cultural heritage objects/monuments must also be considered in addition to their interaction with the cultural heritage (Silence 2010; De Silva and Henderson 2011). A survey carried out in the USA found that over $60 \%$ of conservators believe that their work practices are potentially damaging to the environment with the highest frequency of concern being solvent, chemical, and/or hazardous materials use and disposal (Silence 2010). As well, World Heritage sites must establish sustainable management plans that integrate concerns of both sustainable development and Climate Change into their approach so as to preserve and enhance these sites as a requirement to retain their labels (UNESCO-WHC 2006; UNESCO 2015). Despite the concerns or requirements in using safe or green practices in preservation of museum 
Fig. 15.15 (a and b) A photo of the frying pan before and after treatment with local electrolysis and the corrosion inhibitor L-cysteine applied using a brush. Image: (C) Dr. George Koutsouflakis, Ephorate of Underwater Antiquities.

Author: Susana

Mavroforaki, University of West Attica
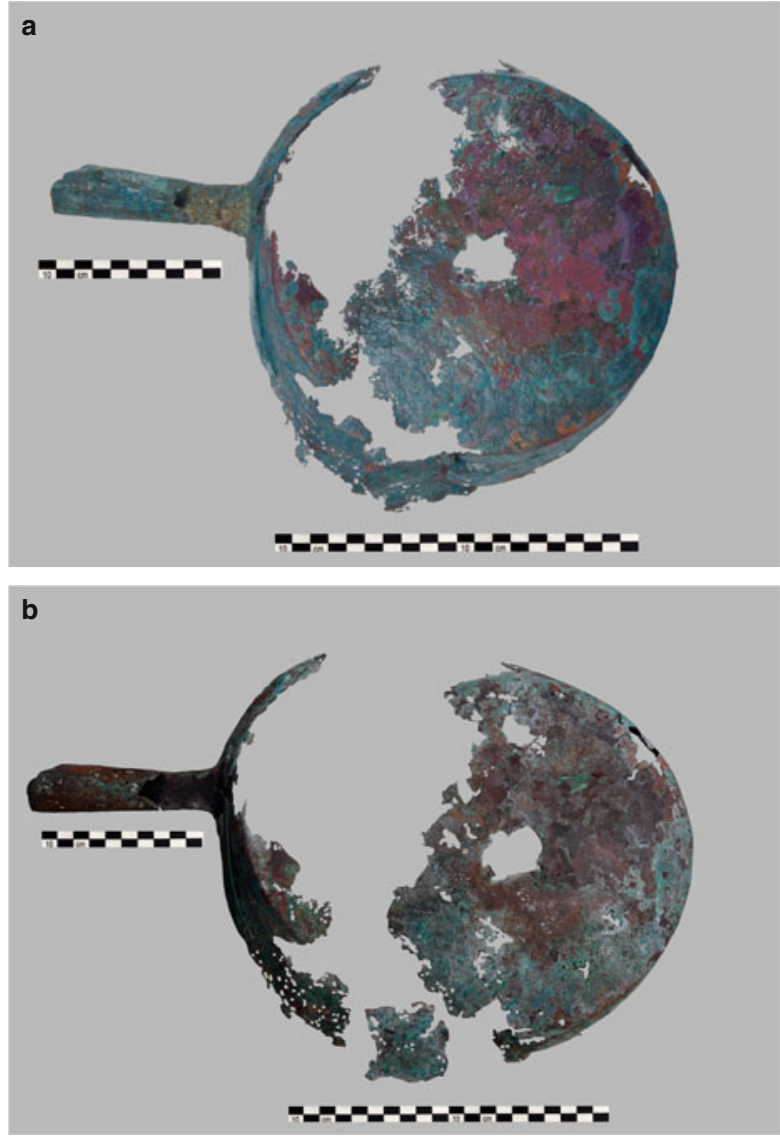

collections and historical sites, the review of the literature for this chapter has found that only certain countries and mostly in the Mediterranean region are focusing their conservation research efforts in testing new green materials for cultural heritage metals. Researchers' sensitivity into investigating green materials for cultural heritage may be due to their living experiences with respect to the effects of climate change in their region (Macchia et al. 2016); a recent report has established that the Mediterranean basin is one of the most prominent hotspots of climate and environmental change with devastating effects on human health and security as well as to its natural ecosystems by 2050 (MedECC 2018).

The chapter has described the state-of-the-art research carried out to date on organic green corrosion inhibitors derived from natural and/or biological sources for conservation. Most of the research is based on plant extracts and oils including amino acids (cysteine). Often the research only investigates the new green inhibitor on metal coupons with and without corrosion products using electrochemical techniques, without further study on real artefacts and on the specific adsorption models and involved mechanisms; a limitation also identified for research into industrial 
applications (Marzorati et al. 2019). According to Marzorati et al. (2019) research for green corrosion inhibitors should aim to characterize the active compound in the green extract so as to be able to reproduce the results, which otherwise can be dependent on the harvesting location, weather conditions, season, harvesting technique, and many other parameters. Finally, for conservation research, all the green inhibitors tested seem to alter the surface colour of metal coupons when applied using immersion methods, which can be reduced using brush application, but are reversible either with water or ethanol.

Some interesting and promising research results were also identified in this review concerning the application of inhibitors from biological sources, such as bacteria and biopolymers. The stabilization of copper alloy artefacts using the biopatina is promising. Also, interestingly, chitosan where the coating formulation includes a corrosion inhibitor was found to be more effective than when the coating processes were applied separately on the metal surface (i.e., corrosion inhibitor followed by coating). This research was in contradiction to research carried out when corrosion inhibitor additives were tested in synthetic coatings, such as Paraloid B72 or Poligen, and none was found to show any clear improvement of the protection properties of the coatings, including one of them impaired the barrier effect of the coating (Argyropoulos et al. 2007a; Cano et al. 2010).

Today, conservators' main concern should be to support sustainable practices in their field in addition to using the most effective protection system on the metals cultural heritage. The conservation principles for appropriate protection systems should include sustainability or green practice in addition to reversibility and minimal surface alterations to the appearance. The authors believe that future research should continue investigation into microorganisms as well as bio-based coatings with green corrosion inhibitors and their ability to work together synergistically to act as long-term protection systems for cultural heritage metals; the evaluation should also include how 'green' is the inhibitor with respect to their production and use (i.e., Life Cycle Assessment). Such research requires studies on real artefacts/monuments using in situ corrosion measurements, such as electrochemical impedance spectroscopy (Barat et al. 2019) or oxygen consumption (Matthiesen 2013). Given the challenges involved in terms of vigorous testing and scientific examination required both on metal coupons and real artefacts and including identifying the specific adsorption models and involved mechanisms, the way forward should be through funded collaborative projects.

Acknowledgements The research for testing new green inhibitors was co-financed by the European Union (European Social Fund, ESF) and Greek national funds through the Operational Program 'Education and Lifelong Learning' of the National Strategic Reference Framework (NSRF)—Research Funding Program: ARCHIMEDES III. Investing in knowledge society through the European Social Fund. Vasilike Argyropoulos would also like to acknowledge the support in writing this publication during her visiting professorship at the University of Toronto, Faculty of Information. 


\section{References}

Abbout S, Meryem Z, Benzidia B, Hammouch H (2018) New formulation based on Ceratonia Siliqua L seed oil, as a green corrosion inhibitor of iron in acidic medium. Anal Bioanal Electrochem 10:789-804

Abdelwahab A, Rifai M, Abdelhamid Z (2018) Corrosion inhibition of bronze alloy by aloe vera extract in neutral media for application on bronze artifacts. In: EuroCorr. EuroCorr, Krakow, p 83

Abu-baker AN (2019) From mono-oxime to tri-oxime: the development of a new group of corrosion inhibitors for copper alloys. In: Chemello C, Brambilla L, Joseph E (eds) ICOMCC METAL 2019, ICOM, Neuchatel, pp 204-211

Abu-Baker AN, Macleod ID, Sloggett R, Taylor R (2013) A comparative study of salicylaldoxime, cysteine, and benzotriazole as inhibitors for the active chloride-based corrosion of copper and bronze artifacts. Eur Sci J 9:1857-7881

Albini M, Letardi P, Mathys L, Brambilla L, Schröter J, Junier P, Joseph E (2018) Comparison of a bio-based corrosion inhibitor versus benzotriazole on corroded copper surfaces. Corros Sci 143:84-92

Anderson KJ (1991) A history of lubricants. MRS Bull 16:69-69

Argyropoulos V (ed) (2008) Metals and museums in the mediterranean. TEI of Athens, Athens

Argyropoulos V, Boyatzis S, Giannoulaki M, Polikreti K (2013) The role of standards in conservation methods for metals in cultural heritage. In: Dillmann P, Watkinson D, Angelini E, Adriaens A (eds) Corrosion and conservation of cultural heritage metallic artefacts. Elsevier, Oxford, pp 478-517

Argyropoulos V, Boyatzis SC, Giannoulaki M, Malea A, Pournou A, Rapti S, Zacharopoulou A, Guilminot E (2018) Preliminary investigation of L-cysteine as a corrosion inhibitor for marine composite artefacts containing copper or iron alloys. In: Williams E, Hocker E (eds) Proceedings of the 13th ICOM-CC group on wet organic archaeological materials conference, Florence 2016, ICOM, pp 282-291

Argyropoulos V, Charalambous D, Kaminari A, Karabotsos A, Polikreti K, Siatou A, Cano E, Bastidas DM, Cayuela I, Bastidas J-M, Degrigny C, Vella D, Crawford J, Golfomitsou S (2007a) Testing of a new wax coating Poligen ES $91009 \AA$ and corrosion inhibitor additives used for improving coatings for historic iron alloys. In: Degrigny C, Langh R van, Joosten I, Ankersmit B (eds) METAL 07: proceedings of the ICOM-CC metal WG Interim meeting, Amsterdam, ICOM-CC, Amsterdam, pp 10-15

Argyropoulos V, Giannoulaki M, Michalakakos GP, Siatou A (2007b) A survey of the types of corrosion inhibitors and protective coatings used for the conservation of metal objects from museum collections in the Mediterranean basin. In: Argyropoulos V, Hein A, Harith MA (eds) Strategies for saving our cultural heritage: papers presented at the international conference on conservation strategies for saving indoor metallic collections with a satellite meeting on legal issues in the conservation of cultural heritage Cairo 25 Febr, TEI of Athens, Athens, pp 166-170

Argyropoulos V, Mavroforaki S, Giannoulaki M, Boyatzis SC, Karabotsos T, Zacharopoulou A, Guilminot E (2017) New approaches in stabilizing chloride-contaminated ancient bronzes using corrosion inhibitors and/or electrochemical methods to preserve information in the patinas. In: JD Lapatin, K, Spinelli A (eds) Artistry in Bronze the greeks and their legacy: acta of the XIX international congress on ancient bronzes. J. Paul Getty Trust, Los Angeles, pp 313-318

Argyropoulos V, Rameau J-J, Dalard F, Degrigny C (1999) Testing Hostacor it as a corrosion inhibitor for iron in polyethylene glycol solutions. Stud Conserv 44:49-57

Argyropoulos V, Selwyn LS, Logan JA (1997) Developing a conservation treatment using ethylenediamine as a corrosion inhibitor for wrought iron objects found at terrestrial archaeological sites. In: MacLeod ID, Pennec SL, Robbiola L (eds) METAL 1995, James \& James (Science Publishers) Ltd., London, pp 153-158 
Barat BR, Letardi P, Cano E (2019) An overview of the use of EIS measurements for the assessment of patinas and coatings in the conservation of metallic cultural heritage. In: Chemello C, Brambilla L, Joseph E (eds) METAL 2019, ICOM-CC, Neuchatel, pp 83-91

Barrera PR, Gómez FJR, Ochoa EG (2019) Assessing of new coatings for iron artifacts conservation by recurrence plots analysis. CoatingsTech 9:12

Benzidia B, Barbouchi M, Hammouch H, Belahbib N, Zouarhi M, Erramli H, Ait Daoud N, Badrane N, Hajjaji N (2018) Chemical composition and antioxidant activity of tannins extract from green rind of Aloe vera (L.) Burm. F. J King Saud Univ—Sci 31(4):1175-1181

Benzidia B, Hammouch H, Dermaj A, Belahbib N, Zouarhi M, Erramli H, Ait Daoud N, Badrane N, Hajjaji N (2019) Investigation of green corrosion inhibitor based on Aloe vera (L.) Burm. F. for the protection of bronze B66 in 3\% NaCl. Anal Bioanal Electrochem 11:165-177

Berthon G (1995) The stability constants of metal complexes of amino acids with polar side chains. Pure Appl Chem 67:1117-1240

Boyatzis SC, Veve A, Kriezi G, Karamargiou G, Kontou E, Argyropoulos V (2017) A scientific assessment of the long-term protection of incralac coatings on ancient bronze collections in the National Archaeological Museum and the Epigraphic and Numismatic Museum, in Athens, Greece. In: JD Lapatin K, Spinelli A (eds) Artistry in Bronze The Greeks and their legacy: acta of the XIX international congress on ancient bronzes. J. Paul Getty Trust, Los Angeles, pp 300-312

Cano E, Bastidas DM, Argyropoulos V, Fajardo S, Siatou A, Bastidas JM, Degrigny C (2010) Electrochemical characterization of organic coatings for protection of historic steel artefacts. $\mathrm{J}$ Solid State Electrochem 14:453

Cano E, Lafuente D (2013) Corrosion inhibitors for the preservation of metallic heritage artefacts. In: Dillmann P, Watkinson D, Angelini E, Adriaens A (eds) Corrosion and conservation of cultural heritage metallic artefacts. Elsevier, Oxford, pp 570-594

Casaletto MP, Figà V, Privitera A, Bruno M, Napolitano A, Piacente S (2018) Inhibition of cor-ten steel corrosion by "green" extracts of Brassica campestris. Corros Sci 136:91-105

Chellouli M, Bettach N, Hajjaji N, Srhiri A, Decaro P (2014) Application of a formulation based on oil extracted from the seeds of Nigella Sativa L, inhibition of corrosion of iron in $3 \% \mathrm{NaCl}$. Int J Eng Res Technol 3:2489-2495

Chellouli M, Chebabe D, Dermaj A, Erramli H, Bettach N, Hajjaji N, Casaletto MP, Cirrincione C, Privitera A, Srhiri A (2016) Corrosion inhibition of iron in acidic solution by a green formulation derived from Nigella sativa L. Electrochim Acta 204:50-59

Church JW, Service NP, Striegel M (2013) Comparative study of rust converters for historic outdoor metalwork. In: Hyslop E, Gonzalez V, Troalen L, Wilson L (eds) METAL 2013, Historic Scotland and International Council of Museums, Edinburgh, pp. 169-174

De Silva M, Henderson J (2011) Sustainability in conservation practice. J Inst Conserv 34:5-15

Degrigny C (2008) The search for new and safe materials for protecting metal objects. In: Argyropoulos V (ed) Metals and museums in the mediterranean. TEI of Athens, Athens, pp $179-231$

Degrigny C, Agryropoulos V, Pouli P, Grech M, Kreislova K, Harith M, Mirambet F, Arafat A, Angelini E, Cano E, Hajjaji N, Cilingiroglu A, Almansour A, Mahfoud L (2007) The methodology for the PROMET project to develop/test new non-toxic corrosion inhibitors and coatings for iron and copper alloy objects housed in Mediterranean museums. In: Degrigny C, Langh R van, Joosten I, Ankersmit B (eds) METAL 07: proceedings of the ICOM-CC Metal WG interim meeting, Amsterdam, ICOM-CC, Amsterdam, pp 31-37

ECHA (2019a) Benzotriazole. https://echa.europa.eu/el/substance-information/-/substanceinfo/ 100.002.177. Accessed 24 Nov 2019

ECHA (2019b) L-cysteine. https://echa.europa.eu/substance-information/-/substanceinfo/100.000. 145. Accessed 26 Nov 2019

El Ibrahimi B, Jmiai A, Bazzi L, El Issami S (2020) Amino acids and their derivatives as corrosion inhibitors for metals and alloys. Arab J Chem 13:740-771 
Elia A, Dowsett M, Adriaens A (2010) On the use of alcoholic carboxylic acid solutions for the deposition of protective coatings on copper. In: Mardikian P, Chemello C, Watters C, Hull P (eds) International conference of metal conservation intereim meeting of the international council of museums committee for conservation metal working group ICOM 2010. Clemson University, Charleston, pp 144-150

Erhardt D, Hopwood W, Padfield T, Veloz N (1984) Durability of incralac, examination of a ten year old treatment. In: ICOM-CC. ICOM, Copenhagen, pp 22.1-22.3

Giuliani C, Pascucci M, Riccucci C, Messina E, Salzano de Luna M, Lavorgna M, Ingo GM, Di Carlo G (2018) Chitosan-based coatings for corrosion protection of copper-based alloys: a promising more sustainable approach for cultural heritage applications. Prog Org Coat 122:138-146

Goni LKMO, Mazumder AJM (2019) Green corrosion inhibitors. In: Singh A (ed) Corrosion inhibitors. IntechOpen, London, p 13

Grattan DW, Gilberg M (1994) Ageless oxygen absorber: chemical and physical properties. Stud Conserv 39:210-214

Gravgaarda M, van Lanschot J (2012) Cysteine as a non-toxic corrosion inhibitor for copper alloys in conservation, J Instit Conserv 35(1):14-24

Hammouch H, Dermaj A, Chebabe D, Decaro P, Hajjaji N, Bettach N, Takenouti H, Srhiri A (2013) Analytical \& Opuntia Ficus Indica seed oil: characterization and application in corrosion inhibition of carbon steel in acid medium. Anal Bioanal Electrochem 5:236-254

Hammouch H, Dermaj A, Goursa M, Hajjaji N, Srhiri A (2007a) New corrosion inhibitor containing Opuntia Ficus Indica seed extract for bronze and iron-based artifacts. In: Argyropoulos V, Hein A, Harith MA (eds) Strategies for saving our cultural heritage. TEI of Athens, Athens, pp 149-155

Hammouch H, Dermaj A, Hajjaji N, Degrigny C, Srhiri A (2007b) Inhibition of the atmospheric corrosion of steel coupons simulating historic and archaeological iron-based objects by cactus seeds extract. In: Degrigny, Langh R van, Ankersmit B, Joosten I (eds) METAL07: proceedings of the ICOM-CC METAL WG interim meeting, Amsterdam, Rijskmuseum, Amsterdam, pp. $56-63$

Hashim Y, Ismail I, Parveen J, Othman R (2014) Production of cysteine: approaches, challenges and potential solution. Int $\mathrm{J}$ Biotechnol Wellness Ind 3:95-101

Hawks C, McCann M, Makos K, Goldberg L, DJr H, Ertel D, Silence P (eds) (2010) Health and safety for museum professionals, 1st edn. Society for the Preservation of Natural History Collections, New York

Hem JD (1960) Complexes of ferrous iron with tannic acid. Chemistry of iron in natural water. Geological survey water-supply paper 1459-D, Washington

Hollner S, Mirambet F, Rocca E, Reguer S (2010) Development of new environmentally safe protection systems for the conservation of iron artefacts. In: Mardikian $\mathrm{P}$, Chemello $\mathrm{C}$, Watters C, Hull P (eds) METAL 2010: proceedings of the interim meeting of the ICOM-CC Metal Working Group, October 11-15, 2010, Charleston, South Carolina, USA, Clemson University, Charleston, pp. 160-166

Iglesias J, García de Saldaña E, Jaén JA (2001) On the tannic acid interaction with metallic iron. Hyperfine Interact 134:109-114

Ismail KM (2007) Evaluation of cysteine as environmentally friendly corrosion inhibitor for copper in neutral and acidic chloride solutions. Electrochim Acta 52:7811-7819

Jmiai A, El Ibrahimi B, Tara A, Oukhrib R, El Issami S, Jbara O, Bazzi L, Hilali M (2017) Chitosan as an eco-friendly inhibitor for copper corrosion in acidic medium: protocol and characterization. Cellulose 24:3843-3867

Joseph E, Simon A, Mazzeo R, Job D, Wörle M (2012) Spectroscopic characterization of an innovative biological treatment for corroded metal artefacts. J Raman Spectrosc 43:1612-1616

Juita DBZ, Kennedy EM, Mackie JC (2012) Low temperature oxidation of linseed oil: a review. Fire Sci Rev 1:3 
Keene S (ed) (1985) Corrosion inhibitors in conservation. The United Kingdom Institute for Conservation, London

Kesavan D, Gopiraman M, Sulochana N (2012) Green Inhibitors for corrosion of metals: a review. Chem Sci Rev Lett 1:1-8

Kooli WM, Junier T, Shaky M, Monachon M, Davenport KW, Vaideeswaran K (2019) Remedial treatment of corroded iron objects by environmental Aeromona isolates. Appl Environ Microbiol 85:1-18

L'Héronde M, Bouttemy M, Mercier-Bion F, Neff D, Apchain E, Etcheberry A, Dillmann P (2019) Multiscale study of interactions between corrosion products layer formed on heritage cu objects and organic protection treatments. Heritage 2:2640-2651

Larios-Galvez AK, Porcayo-Calderon J, Salinas-Bravo VM, Chacon-Nava JG, GonzalezRodriguez JG, Martinez-Gomez L (2017) Use of Salvia hispanica as an eco-friendly corrosion inhibitor for bronze in acid rain. Anti-Corrosion Methods Mater 64:654-663

Leal DA, Riegel-Vidotti IC, Ferreira MGS, Marino CEB (2018) Smart coating based on double stimuli-responsive microcapsules containing linseed oil and benzotriazole for active corrosion protection. Corros Sci 130:56-63

Logan J (2014) Government of Canada. In: Tann. acid Coat. rusted iron artifacts, Former. Publ. under title Tann. acid Treat.-Can. Conserv. Inst. Notes 9/5. https://www.canada.ca/en/ conservation-institute/services/conservation-preservation-publications/canadian-conservationinstitute-notes/tannic-acid-rusted-iron-artifacts.html. Accessed 24 Nov 2019

Macchia A, Luvidi L, Fernanda P, Russa MFL, Ruffolo S (2016) Green conservation of cultural heritage. International workshop. Int J Conserv Sci 7:185-357

Madsen HB (1967) A preliminary note on the use of benzotriazole for stabilizing bronze objects. Stud Conserv 12:163-167

Malik MA, Hashim MA, Nabi F, AL-Thabaiti SA, Khan Z (2011) Anti-corrosion ability of surfactants: a review. Int J Electrochem Sci 6:1927-1948

Marzorati S, Verotta L, Trasatti SP (2019) Green corrosion inhibitors from natural sources and biomass wastes. Molecules 24:48

Mathias C, Ramsdale K, Nixon D (2004) Saving archaeological iron using the revolutionary preservation system. In: Ashton J, Hallam D (eds) METAL 04: proceedings of the international conference on metals conservation, National Museum of Australia, Canberra, pp. 28-42

Matthiesen H (2013) Oxygen monitoring in the corrosion and preservation of metallic heritage artefacts. In: Dillmann P, Watkinson D, Angelini E, Adriaens A (eds) Corrosion and conservation of cultural heritage metallic artefacts. Elsevier, Oxford, pp. 368-391

MedECC (2018) 1st Scientific assesment report about climate change and environmental change in the mediterranean. http://planbleu.org/sites/default/files/upload/files/EN_Press\%20summary\% 20report\%20medecc.pdf. Accessed 24 Nov 2019

Montemor MF (2016) Fostering green inhibitors for corrosion prevention. In: Hughes A, Mol J, Zheludkevich M, Buchheit R (eds) Active protective coatings. Springer Ser Mater Sci, vol 233. Springer, Dordrecht. https://doi.org/10.1007/978-94-017-7540-3_6

Otieno-Alego V, Creagh DC, Heath GA (2004) Avoiding thiourea: L-methionine methyl ester as a non-toxic corrosion inhibitor for mild steel artefacts in citric acid pickling solutions. In: MacLeold ID, Theile JM, Degrigny C (eds) ICOM-CC METAL 2001, Western Australian Museum, Perth, pp. 304-309

Pandya A, Singh JK, Singh DDN (2016) An eco-friendly method to stabilize unstable rusts. In: Menon R, Chemello C, Pandya A (eds) ICOM-CC METAL 2016, ICOM, New Delhi, pp. 136-143

Pant AF, Sangerlaub S, Muller K (2017) Gallic acid as an oxygen scavenger in bio-based multilayer packaging films. Materials (Basel) 10(5):489

Pavlopoulou L-C, Watkinson D (2006) The degradation of oil painted copper surfaces. Stud Conserv 51:55-65

Pelikan JB (1966) Conservation of iron with tannin. Stud Conserv 11:109-115 
Popoola LT (2019) Organic green corrosion inhibitors (OGCIs): a critical review. Corros Rev 37:71-102

Raja AS, Venkatesan R, Sonisheeba R, Paul JT, Sivakumar S, Angel P, Sathiyabama J (2014) Corrosion inhibition by cysteine-an over view. Int J Adv Res Chem Sci 1:101-109

Rani BEA, Basu BBJ (2012) Green inhibitors for corrosion protection of metals and alloys: an overview. Int J Corros 2012:1-15

Rocca E, Faiz H, Dillmann P, Neff D, Mirambet F (2019) Electrochemical behavior of thick rust layers on steel artefact: mechanism of corrosion inhibition. Electrochim Acta 316:219-227

Rocca E, Mirambet F (2007) Corrosion inhibitors for metallic artefacts: temporary protection. In: Dillmann P, Beranger G, Piccardo P, Matthiesen H (eds) Corrosion of metallic heritage artefacts. Elsevier, Oxford, pp 308-334

Sabin AH (1904) The industrial and artistic technology of paint and varnish. Wiley \& Sons, New York

Schrager KK, Sobelman J, Kingery-Schwartz A (2017) Not a known carcinogen. In: American Institute for Conservation 45th annual meeting on May 31st 2017

Sharma SK, Sharma A (2012) Green corrosion inhibitors: status in developing countries. In: Sharma SK (ed) Green corrosion chemistry and engineering: opportunities and challenges, 1st edn. Wiley-VCH Verlag GmbH \& Co. KGaA, Weinheim, Germany, pp 157-180

Shehata OS, Korshed LA, Attia A (2018) Green corrosion inhibitors, past, present, and future. In: Aliofkhazraei M (ed) Corrosion inhibitors, principles and recent applications. IntechOpen, London, $\mathrm{p} 6$

Silence P (2010) How are US conservators going green? Results of polling AIC members. Stud Conserv 55:159-163

Thurrowgood D, Otieno-Alego V, Pearson C, Bailey G (2004) Developing a conservation treatment using linear dicarboxylates as corrosion inhibitors for mild steel in wash solutions following citric acid stripping. In: MacLeod ID, Theile JM, Degrigny C (eds) ICOM-CC METAL 2001, Western Australian Museum, Perth, pp. 310-315

Turner SJ (1985) Surface treatments for local history collections. In: Keene S (ed) Corrosion inhibitors in conservation. United Kingdom Institute of Conservation, London, pp 29-30

UNESCO (2015) Policy for the integration of a sustainable development perspective into the processes of the world heritage convention. http://whc.unesco.org/en/sustainabledevelopment/ . Accessed 21st November 2019

UNESCO-WHC (2006) Issues related to the state of conservation of world heritage properties: the impacts of climate change on world heritage properties. Decision 30 COM 7:1

Varvara S, Bostan R, Bobis O, Găină L, Popa F, Mena V, Souto RM (2017) Propolis as a green corrosion inhibitor for bronze in weakly acidic solution. Appl Surf Sci 426:1100-1112

Verma C, Ebenso EE, Bahadur I, Quraishi MA (2018) An overview on plant extracts as environmental sustainable and green corrosion inhibitors for metals and alloys in aggressive corrosive media. J Mol Liq 266:577-590

Vieira AP, Berndt G, De Souza Junior IG, Quraishi MA (2011) Adsorption of cysteine on hematite, magnetite and ferrihydrite: FT-IR, Mössbauer, EPR spectroscopy and X-ray diffractometry studies. Amino Acids 40:205-214

Wang T, Wang J, Wu Y (2015) The inhibition effect and mechanism of 1-cysteine on the corrosion of bronze covered with a $\mathrm{CuCl}$ patina. Corros Sci 97:89-99

$\mathrm{Xu}$ W, Han EH, Wang Z (2019) Effect of tannic acid on corrosion behavior of carbon steel in $\mathrm{NaCl}$ solution. J Mater Sci Technol 35:64-75

Zacharopoulou A, Batis G, Argyropoulou V, Guilminot E (2016) The testing of natural corrosion inhibitors cysteine and mature tobacco for treating marine composite objects in PEG400 solutions. Int J Conserv Sci 7:259-264

Zouarhi M, Chellouli M, Abbout S, Hammouch H, Dermaj A, Said Hassane SO, Decaro P, Bettach N, Hajjaji N, Srhiri A (2018) Inhibiting effect of a green corrosion inhibitor containing jatropha curcas seeds oil for iron in an acidic medium. Port Electrochim Acta 36:179-195 
Open Access This chapter is licensed under the terms of the Creative Commons Attribution 4.0 International License (http://creativecommons.org/licenses/by/4.0/), which permits use, sharing, adaptation, distribution and reproduction in any medium or format, as long as you give appropriate credit to the original author(s) and the source, provide a link to the Creative Commons license and indicate if changes were made.

The images or other third party material in this chapter are included in the chapter's Creative Commons license, unless indicated otherwise in a credit line to the material. If material is not included in the chapter's Creative Commons license and your intended use is not permitted by statutory regulation or exceeds the permitted use, you will need to obtain permission directly from the copyright holder. 